\title{
Discursos mediáticos versus discursos sociales en la Argentina contemporánea
}

\section{Cora Cecilia Arias ${ }^{1}$}

\author{
Fecha de recepción: 17 de junio de 2013
}

Fecha de aprobación: 17 de octubre de 2013

\begin{abstract}
Resumen:
Este artículo reflexiona sobre las estrategias recreadas por los medios de comunicación a la hora de informar los conflictos sociales. Con ese objetivo, se selecciona una protesta sindical de gravitante resonancia pública en la Argentina: el paro de subterráneos de la Ciudad de Buenos Aires de abril de 2004. Se contrastan y ponen en tensión los discursos de los protagonistas de esa experiencia con los discursos emitidos por la televisión sobre ese caso. De esta manera, y entendiendo a los medios de comunicación como agentes de control social, se resaltan los sentidos y significados políticos que la televisión vehiculizó sobre ese conflicto social.
\end{abstract}

Palabras clave: Discurso; televisión; protesta; conflicto sindical.

\begin{abstract}
:
This article is a reflection on the strategies the media use to inform of social conflicts. It takes a union protest widely covered in Argentina, namely the subway workers strike in Buenos Aires in April 2004. Discourses by the protagonists are contrasted with discourses broadcasted on television. Understanding the media as agents for social control, the political senses and meanings television transmitted on this case are highlighted.
\end{abstract}

Key words: discourse; television; protest; union conflict

1 Licenciada en Ciencia Política (Universidad de Buenos Aires). Doctoranda en Ciencias Sociales (Facultad de Ciencias Sociales-UBA). Docente universitaria (UBA). Instituto de Investigaciones Gino Germani, Universidad de Buenos Aires, Azcuénaga 1038, piso 6, departamento H., Ciudad Autónoma de Buenos Aires. Código postal: 1115, coracearias@gmail.com. 


\section{Introducción}

“...generalmente cuando todo el camino previo, la apertura de molinetes, repartir volantes, generalmente los conflictos se resuelven únicamente cuando el hilo se tensa tanto que se va a romper, y eso es cuando hay un paro y entonces los medios te muestran eso, pero pará; no te muestran todo el recorrido previo, de que vos hiciste un montón de medidas, donde ellos no estuvieron, o no se interesaron, y que no es que a nosotros nos encanta parar de una porque sí, sino porque muchas veces es la única forma en que te escuchen y se resuelva."

Estos relatos corresponden a representantes de la Comisión de prensa del sindicato del subte (la Asociación Gremial de los Trabajadores de Subte y Premetro), y demarcan el problema que abordaremos en este artículo. Se trata de reflexionar acerca del papel de los medios de comunicación masivos a la hora de fijar sentidos políticos y sociales sobre los conflictos sociales. Los medios de comunicación capturan, representan y califican las acciones de los sectores subalternos. En esta contribución nos ocuparemos del conflicto de los trabajadores del subterráneo de la Ciudad de Buenos Aires, focalizándonos en un acontecimiento significativo en la historia de esa experiencia: el "paro por las seis horas" de abril de 2004, y los sentidos que la televisión vehiculizó en esa ocasión.

El objetivo de nuestro trabajo será cotejar y contrastar dos discursos que relatan ese conflicto puntual: el de los protagonistas de la experiencia y el de la televisión. Para ello, planteamos el abordaje de dos tipos de corpus distintos que, a la vez, exigen herramientas metodológicas diferentes: por un lado, el análisis de imágenes televisivas dedicadas a la protesta, y por el otro, el análisis de entrevistas a protagonistas de la experiencia y de documentos elaborados por el sindicato, publicados en sitios de Internet. Estos dos análisis se confrontan luego, porque entendemos que es básicamente allí donde se hacen evidentes las distancias entre el discurso hegemónico y los discursos de los protagonistas del conflicto. 


\section{El conflicto desde los relatos de sus protagonistas}

Con la concesión del servicio de subterráneos a Metrovías, en el año 1994, se produjo un retraimiento de las condiciones de labor en desmedro de los trabajadores. Uno de los emergentes principales de ese retraimiento consistió en la ampliación de la jornada de trabajo a ocho horas. Este hecho fue de gran trascendencia puesto que históricamente la jornada nunca había excedido las seis horas, a excepción del período de la dictadura donde se extendió a siete. La extensión de la jornada se realizó de manera paulatina a través de la utilización de la fórmula seis horas de trabajo más dos de horas extras, hasta la firma del nuevo Convenio colectivo de trabajo refrendado por la Unión Tranviarios Automotor. Así lo relata un delegado en una entrevista:

Cuando nosotros nos juntábamos, éramos jóvenes y empezaron a venir o empezábamos a escuchar a los que habían quedado de subterráneos. Ahí nos enteramos que existían unas seis horas, de la seguridad, por ejemplo, los boleteros de los subterráneos cobraban unos 870 pesos y nosotros ahora 405 pesos, y nosotros esto no lo sabíamos. Por ejemplo, cuando empezamos a hablar con confianza, me vino como un trauma que hasta el 31 de diciembre del año 93 trabajaba seis horas y el primero de enero ¡había que trabajar ocho horas!, y eso anímicamente nos derrotó. Si quedaba alguna esperanza el año 94, 95, 96... Para ellos era muy doloroso, y después algunos se fueron retirando porque por ahí la empresa lo ofrecía, y no sé si quedará alguno, creo que no queda nadie en alguna línea. [...] Fue una derrota muy grande y nos llegaron a contar. Por eso nosotros cuando empezamos a organizarnos más en la línea nos planteamos recuperar las seis horas. Eso fue nuestra máxima, en ese periodo de lucha lo que queríamos hacer es la efectividad, que no haya más despidos. Después la Empresa empezó a hacer despidos muy específicos a candidatos a delegados o activistas y nosotros nos presentamos en el 96. 
Como consecuencia del desarrollo de un conjunto de acciones políticas integradas en una planificación estratégica -que incluyó: la presentación de tres proyectos de ley orientados a la declaración del trabajo como insalubre y el consecuente restablecimiento de la jornada de seis horas, la organización de reuniones multisectoriales en las que se debatía el problema y se elaboraban documentos que luego se hacían públicos, la convocatoria a asambleas para decidir medidas de protesta-, el Cuerpo de delegados logró revertir parcialmente aquel retraimiento de las condiciones de labor.

Esa reversión se cristalizó en dos conquistas: en el mes de septiembre de 2003, se obtuvo la declaración de la insalubridad del trabajo y la consecuente "recuperación" de la jornada de seis horas para la población de los trabajadores que se desempeñaban en los establecimientos en los que se habían detectado condiciones insalubres. Y, en el mes de abril de 2004, en el marco del proceso de conciliación obligatoria impuesto por el gobierno nacional tras cuatro jornadas de paro, se logró extender la jornada de seis horas a todo el personal, modificándose el convenio colectivo que admitía el régimen general de ocho horas.

Describamos en detalle el proceso: la lucha por las seis horas fue impulsada en 2001 por el Cuerpo de delegados y sin apoyo del sindicato pese al requerimiento explícito de los trabajadores. Promediando ese año comenzó a diligenciarse la vía legislativa con la presentación del proyecto de ley 871 . El clima social propiciado por el estallido de 2001 actuó como comburente: las movilizaciones se multiplicaron hasta adquirir frecuencia semanal. Un año después de impulsado, el proyecto fue aprobado en la Legislatura. Más tarde, haciendo uso de sus facultades -y fruto de la petición empresaria-, el Jefe de gobierno vetó el proyecto. La ley sólo podía ser refrendada a través del voto de dos tercios de la Legislatura. Los pronósticos desalentadores no paralizaron la movilización de más de un centenar de trabajadores al recinto el día de la votación. Tras una sangrienta represión policial, la ley 
no fue aprobada y la movilización se desaceleró en el mediano plazo. Casi un año después, aprovechando un resquicio abierto por la coyuntura política, se aprobó el proyecto de ley con sólo una amenaza de paro.

Así, el 5 de septiembre de 2003 se consigue la firma del retorno a la jornada de seis horas por parte de la Oficina de la Policía de Trabajo para el área de túneles y talleres, al tiempo que se crea una comisión de investigación para determinar si efectivamente existían condiciones de insalubridad en el sector. Se trataba de una conquista parcial, porque la disposición excluía al sector de boleterías, Premetro y algunos talleres, dejando a un total de casi 600 personas fuera de la resolución.

En un primer momento, ante la negativa de la empresa a reorganizar la planificación horaria, el Cuerpo de delegados decide impulsar la aplicación unilateral de la disposición, respaldándose en presentaciones legales hechas en base al decreto promulgado. Unos días después, el gobierno dispuso un lapso de un mes de retorno a la jornada de ocho horas para permitir a la empresa la reorganización del personal. En los meses siguientes la principal preocupación política del Cuerpo de delegados fue lograr la igualación de la jornada para todos los sectores; en abril de 2004 este proceso se aceleraría forzando una resolución definitiva del conflicto. A contramano de los objetivos políticos del Cuerpo de delegados, la UTA, de manera sorpresiva, firma en el Ministerio de Trabajo un acuerdo con la empresa en el que se estipulaba una jornada de siete horas para los boleteros junto con la introducción de máquinas expendedoras de pasajes en las estaciones. La dirección del sindicato tardó en comunicar a los delegados el contenido del acuerdo. Disconformes con lo que se había firmado, los trabajadores decidieron parar el subte el viernes 2 de abril a media tarde. Para garantizar el paro, algunos trabajadores cortaron las vías, apelando a la acción directa. De esta manera, el servicio quedaba completamente bloqueado y el personal jerárquico no podía poner en funcionamiento los trenes. 
De esta manera empieza lo que tiempo después será reconocido por los principales militantes como el conflicto más importante en la historia del subterráneo. La huelga duró cuatro días y se trató de un paro activo, que incluyó la toma y permanencia en el lugar de trabajo todo el tiempo que duró la medida de fuerza. La llegada masiva de telegramas de despido después de unas horas de iniciada la huelga y las amenazas de desalojo radicalizaron las decisiones, instalando una disputa a todo o nada que se tradujo en la toma de las cabeceras de las líneas para garantizar la efectividad de la protesta. Después de 80 horas de paralización del servicio, en lo que fue la huelga más larga en la historia del subterráneo hasta ese momento, se logra un acuerdo a favor de los reclamos planteados por los trabajadores. Los despedidos son reincorporados, se entabla el compromiso de no instalar más máquinas expendedoras y se decreta la reducción horaria a seis horas para todos los sectores (con la posibilidad de hacer dos horas extras de manera voluntaria). La agrupación Asociación de Trabajadores de Metrovías, el 8 de abril de 2004 publicó en su blog el siguiente relato del conflicto:

\section{Huelga en ascenso}

La huelga se venía fortaleciendo sistemáticamente. Cada hora se integraban más trabajadores a los piquetes en las cabeceras para impedir la salida de los trenes. Se constituyeron comisiones de solidaridad con vecinos, piqueteros y estudiantes en cada una de las cinco cabeceras.

Los intentos patronales para quebrar la lucha fracasaron. Intentó desalojar los túneles ocupados por los obreros con la policía, montar provocaciones usando la bronca de los pasajeros, mover trenes por tramos cortos con jefes.

Todo esto fracasó por la firme resistencia obrera y el creciente apoyo popular. Entre los colectiveros, también afiliados a la UTA, hubo una fuerte corriente de simpatía hacia los huelguistas del subte. Cuando se preanunciaba el triunfo, los colectiveros 
que pasaban frente al Ministerio de Trabajo tocaban bocinazos de apoyo y festejo. Lo mismo ocurría en las cabeceras de las líneas de colectivos.

Con independencia de que la declaración de insalubridad tuvo como efecto directo la reducción del tiempo de trabajo, la "Campaña por la Seis Horas" demarcó un espacio al interior de la agenda de confrontación del Cuerpo de delegados en el que se problematizó la cuestión de la salud. Aquel conjunto de acciones delinearon un horizonte de visibilidad para los problemas vinculados a la salud y seguridad en el trabajo, que no se desdibujó una vez obtenida, en palabras de un delegado, la "victoria rápida" de la jornada. Por el contrario, el análisis de ese proceso social en particular y, más generalmente de los cursos de acción movilizados por el Cuerpo de delegados en el marco de una estrategia de confrontación contra Metrovías, da cuenta de la instalación del problema de la salud en el programa de transformaciones que compone la agenda de esa autoridad sindical.

\section{Las narrativas televisivas del conflicto}

El corpus que analizaremos está compuesto por diferentes secuencias audiovisuales extraídas de los cinco principales canales argentinos de cable dedicados a la información (Todo Noticias, Crónica Televisión, 26 TV, América 24 y C5N). Centraremos nuestra atención en extractos de archivos audiovisuales referidos a los momentos del paro de los trabajadores del subte de abril de 2004 que describimos en el apartado anterior para rastrear allí las operaciones recreadas por los distintos canales para cumplir con su promesa de informar "la verdad". Más allá de que existen marcadas diferencias entre los canales seleccionados -debido quizás a los grupos económicos que los sustentan, al perfil de audiencia al que están dirigidos, a posicionamientos ideológicos, entre otros-, consideramos que a los efectos de este análisis no aparecen significativas discrepancias en términos de las estrategias utilizadas; es por eso que decidimos estudiarlas como una totalidad. 
Las narrativas periodísticas construyen cada una de las protestas como acontecimiento (Alsina, 1989) ubicándolas en la línea de una lógica de irrupción espasmódica en el espacio de lo público, mientras que los relatos de las experiencias de los actores involucrados se inscriben como eventos en una serie histórica de tiempos largos ligada a la memoria de una(s) experiencia(s) de la dominación y de la contestación.

Así, al visualizar las distintas secuencias de imágenes de los cuatro días de paro de abril de 2004, lo primero que gravita sustancialmente es la jerarquía otorgada a esta noticia por los medios. En la mayoría de los canales, al inicio del día -puntualmente a las 7 de la mañana- se emiten programas con la información que la audiencia debe tener "antes de salir de su casa", para saber "cómo encarar su día". Estas emisiones ubican en primer lugar de importancia lo referido al clima y al tránsito, por eso la paralización de un servicio público se coloca en la primera plana de las noticias y ocupa mucho tiempo en la transmisión. En este sentido, al analizar las emisiones que hacen referencia a un conflicto sindical, es sugerente determinar si la noticia hace eje en las causas políticas de la protesta o, por el contrario, en los efectos que provoca la medida de fuerza y el perjuicio ocasionado al tercero damnificado (Barthes, 1980).

¿Cómo se informa este conflicto? Los conductores de los noticieros matutinos abren sus programas dedicando varios minutos a describir los problemas de tránsito de la ciudad derivados de la ausencia de subtes. Como estrategia autentificante, estos canales poseen cámaras dispuestas en las principales autopistas de ingreso a la Ciudad de Buenos Aires, y parten la pantalla para mostrar las largas colas de automóviles que existen en cada uno de esos accesos. Es decir que, en términos de jerarquización de la información, los problemas en el tránsito revisten la mayor importancia.

Luego la información se traslada hacia el "lugar de los hechos" y automáticamente podemos ver en las pantallas el cartel 
de "en vivo y en directo" tan distintivo de este género. Según Jost (2003), el "directo" o el "vivo" son portadores de una promesa ontológica de autenticidad, por eso los canales no dudan en estamparlo en sus imágenes incluso cuando es falso. Los canales disponen cámaras en diferentes estaciones de los subterráneos, por lo general en las cabeceras de cada línea, para mostrar la ausencia de pasajeros. Hasta allí se trasladan periodistas que relatan desde el lugar y al tiempo que se suceden los hechos.

Los "movileros" (los periodistas que se trasladan hacia el lugar de los hechos, que no están en los estudios de televisión sino que transitan por las calles), cumplen un rol trascendental en la estrategia de los canales. Por un lado, son los más cercanos al conflicto y pueden transmitirlo de manera verídica. Y por otro, son los encargados de recabar los distintos testimonios de las personas afectadas por el paro en cuestión. Según Farré (2004), en los noticieros actuales se promueve la participación de la audiencia, incluso dentro del programa. La televisión ya no es un lugar en el que se transmite un saber o un contenido, sino un lugar de encuentro donde todas las opiniones tienen valor. En el neonoticiario también se suscita la participación del espectador de diversos modos: llamadas telefónicas inician la investigación periodística, los testimonios anónimos son la fuente principal de muchas noticias, en el programa los conductores le dirigen actos de habla al espectador y lo implican en el proceso informativo cuando, por ejemplo, los analistas y expertos transmiten un saber al conductor, quien se entera -o simula hacerlo- a la vez que el televidente.

Si lo importante es mostrar "cómo viaja la gente", entonces los movileros van en búsqueda de testigos que den cuenta de eso. Se trasladan hacia las largas colas que se forman en las paradas de los colectivos e interrogan a los pasajeros, en general de manera tendenciosa. Citamos algunos ejemplos de reportajes:

Movilero: ¿Qué piensa de esta situación?

Pasajero: Creo que todos tienen derecho a reclamar. 


\section{M: Pero...}

P: Sí, nos perjudica para viajar;

Movilero: ¿Quién viaja mejor: la gente o el ganado?

Movilero: ¿Su jefe contempla la llegada tarde?

Movilero: ¿Viajar hoy es igual a todos los días?

Por supuesto que todos los testimonios recogidos pertenecen a pasajeros que se encuentran indignados por la complicación que trae aparejada la ausencia de subtes.

Las intervenciones de los periodistas, tanto de los que informan desde el estudio como de aquellos que recorren las calles, se caracterizan por la apelación a una de las estrategias distintivas de la televisión actual: invocar la cotidianidad del espectador. En ese sentido, implican al público desde frases del estilo "esto nos afecta a todos", "a usted que necesita llegar a su trabajo, al médico o a estudiar", "escuchemos las voces de los trabajadores que pierden su presentismo por culpa de la huelga", etc. Lo importante es "cómo la gente viaja hoy", se informa a cada instante y desde la pantalla las demoras en los distintos transportes, la salida o no de alguna formación de subterráneos, incluso en uno de los canales ubican al lado del característico reloj otro con la cantidad de horas que lleva el paro.

La gente "común", los ciudadanos, la sociedad, constituyen el "nosotros" que representa un sujeto en el medio y víctima, a la vez, de las medidas de fuerza sindicales. Es la gente la que sufre con la radicalización de la protesta. La gente, que también trabaja, debe soportar el caos del tránsito y las arbitrariedades de "unos pocos" que socavan sus derechos a la libre circulación (derecho que para los medios está antes y por sobre el derecho a la protesta). Según estas emisoras de televisión, los pasajeros reaccionan indignados ante un hecho que los toma por sorpresa, una medida impulsada por "una minoría de izquierda radicalizada disconforme con un arreglo que parece ser beneficioso para todo el personal". 
De manera estratégica, la televisión convierte a la gente "ajena al conflicto" en un tercer actor: el pasajero o usuario. En términos de Barthes (1980), la burguesía pone en el escenario del conflicto a un personaje que se opone al huelguista: el hombre de la calle, el contribuyente que se ve perjudicado por la huelga pero no sabe las causas del conflicto. La dinámica de construcción de los sentidos sociales otorgados a las medidas de fuerza se erige desde el establecimiento de la antinomia que Barthes (1980) define en términos de usuario/trabajador. Esta es una figura característica de las narrativas mediáticas y hace hincapié en la oposición entre la figura de trabajador organizado que hace huelga, frente al individuo atomizado, representado como uno de los principales perjudicados por la medida de fuerza. Con el uso de los términos gente, usuario, pasajero, ciudadano (se entiende que ciudadanos no son los trabajadores de paro), la atomización de los intereses individuales se impone a expensas de cualquier sentimiento de pertenencia a un colectivo social.

Ahora bien, hasta aquí nada se ha informado sobre el conflicto en sí, sobre sus causas y sus protagonistas. Sólo en algunas oportunidades se relata la situación, utilizando modelos explicativos simplificantes. Por lo general se tiende a descontextualizar y deshistorizar la situación, anulando el proceso de más larga data. Además, se describe a los protagonistas estableciendo una síntesis homogeneizante y utilizando un vocabulario peyorativo y en ocasiones delictual: "los rebeldes", "los zurdos", "los delegados disidentes", "los piqueteros", entre otros. Y se describen como "víctimas" de los protagonistas del paro a los pasajeros, a quienes mayoritariamente se los tilda como "rehenes". De esta manera, puede decirse que una representación es algo típico, característico o "representativo" de un grupo, pero cuando una serie limitada de rasgos se presentan repetidamente para hablar del mismo grupo, estamos en presencia de la creación de estereotipos: imagen convencional que se ha acuñado para un grupo social. Es decir, se trata de representar a un determinado grupo social haciendo hincapié en algunas 
características y descartando otras; este recorte, como tal, es arbitrario y subjetivo. Sin embargo, esta imagen que construyeron los medios cuenta con el consenso de la audiencia porque está arraigada en la realidad observable convirtiéndose el estereotipo en un modo "natural" y "obvio" de presentar la realidad. Tomemos un ejemplo: si la televisión habla del usuario como "rehén" de la protesta, como contraparte estará representando al "huelguista" como "delincuente" que viola los derechos democráticos de la mayoría. Así, los que reclaman parecen no ser trabajadores del subte; es más, parecen no tener intereses propios sino que estarían sometidos a los de los "caudillos" de izquierda, "una minoría radicalizada que no respeta a la mayoría de la sociedad".

Bajo la mediación de los medios de comunicación social, emerge un espacio en el que se puede elaborar, construir, reforzar o modificar representaciones a partir de las formas ideológicas vinculadas a determinadas estrategias discursivas como es el caso de la retórica a modo de mecánica persuasiva que busca inocular ciertas nociones positivas (aceptación) o negativas (rechazo) de un fenómeno social. Esta estrategia discursiva, sustentada en el plano ideológico dominante existente en toda interacción social, produce una concentración de opiniones e imágenes capaces de expresar, indicar o acentuar algunas características de un acontecimiento que vayan en directa relación con la intencionalidad propuesta en el enunciador.

La noticia de una huelga en los subterráneos ocupa la pantalla durante todo el día, y resuena el problema que los usuarios tienen para movilizarse en la ciudad a cada instante. Con placas en rojo y música de suspenso se visualizan titulares que indican: "Alerta", "Urgente", "Último momento", para anunciar el paro. Pero, ¿qué es lo mostrable o lo visible de un paro? Las imágenes que se emiten son aquellas que muestran las largas colas de pasajeros con caras de hartazgo en las paradas de colectivos, los colapsos en el tránsito o algún incidente o momento de tensión 
que se haya producido- ya sea con algún pasajero o con los delegados.

Por último, queremos hacer referencia a los zócalos que se ubican en las pantallas de estas emisoras al tiempo que se muestran las imágenes del paro y se relata la situación. Transcribimos los más significativos que dejan traslucir cuáles son los sentidos político/sociales que los medios de comunicación masivos otorgan a este conflicto: "Dolor de cabeza para viajar en subte", "Empieza a notarse el mal humor en un día de calor" (mientras se muestran los rostros de pasajeros y los colectivos desbordados de gente), "Buenos Aires ciudad del caos”, “Un grupo minúsculo de trabajadores decide por muchos que necesitan el servicio", "Abajo el conflicto, arriba el caos", "Lo importante es cómo hará usted mañana para viajar".

En suma, los procesos de estereotipación, categorización y clasificación característicos de las producciones mediáticas masivas, amarradas a la lógica comercial, reducen y simplifican las complejidades de las temáticas sin reponer los procesos históricos o los debates de la literatura especializada que permitirían a sus audiencias tener una mirada más amplia e integral de los fenómenos sociales.

\section{Comentarios finales}

Los esquemas narrativos de las noticias que analizamos verifican que los periodistas caen en rutinas demasiado mecanizadas y repetitivas, a partir de ciertos modelos funcionales para entender algunos acontecimientos. Por ejemplo, en nuestro caso de estudio la explicación de una protesta aparece desde el encuadre de la "oposición", que resalta los argumentos polémicos, más espectaculares, pasionales. En esos esquemas interpretativos que se reiteran, se afirma siempre el mismo tipo de relación entre los sujetos sociales, sin mucho lugar para un cambio posible. En este sentido, el conflicto se descontextualiza, se despolitiza y al repre- 
sentarlo se recurre a esquemas clásicos explicativos de criminalización de la protesta social . Así, la neutralización del conflicto (Günther, 2007) está presente en la omisión de todo el universo que está detrás de las huelgas: en ningún momento se exponen con claridad las causas de la protesta (o se las relega a un segundo plano, o se las deslegitima al tomar sólo las explicaciones de los voceros de la empresa).

Asimismo, concebir a los medios como actores sociales y políticos fundamentales en los procesos de construcción hegemónica, así como pensar a sus narrativas como el modo de poner en acción una particular vehiculización de sentidos sociales, nos permitió reflexionar tanto sobre aquello que es definido como legítimo o ilegítimo en cada momento histórico y sobre quién lo intenta definir de ese modo. Barthes realizó un extenso análisis de los discursos (míticos) difundidos por los medios masivos que se presentan como naturales, es decir, que borran las huellas causales de su dominio, que eliminan la génesis, el proceso y la historia para presentarse como "autoevidentes". Este autor pretende dar cuanta "de la mistificación que transforma la cultura pequeñoburguesa en naturaleza universal", es decir, que presenta con total naturalidad "una realidad que no por ser la que vivimos deja de ser histórica" (1980, p. 65). En este sentido, naturaleza e historia se confunden en el discurso de los medios; operatoria que para Barthes constituye un abuso ideológico.

Para identificar las estrategias de la televisión al transmitir el paro de los trabajadores de subterráneos en abril de 2004, apelamos al análisis de otras fuentes que nos permitieron visibilizar el fenómeno en toda su complejidad y reponer los elementos que los medios dejaron afuera. Con este objetivo recuperamos las voces de los protagonistas en diversas entrevistas realizadas, y al mismo tiempo consultamos los medios alternativos (blogs, páginas de Internet, radios) que los trabajadores recrean.

Nos interesa resaltar, finalmente, que si bien la operación mediática de inclusión de un tema en la agenda reviste importancia 
porque le otorga visibilidad a la cuestión, consideramos que es fundamentalmente en los modos de construcción de las noticias y en la organización de los mensajes donde es posible hallar los indicios para interpretar el sentido general de las representaciones mediáticas. Porque antes que detentar un discurso propio, los medios de comunicación masivos representan la nomenclatura de aquellos actores que tienen suficiente capacidad (poder) de nombrar y, por este medio, otorgar existencia a un sujeto o evento.

\section{Bibliografía}

Alsina, Miguel Rodrigo (1989): La construcción de la noticia. Madrid, Paidós.

Arias, Cora Cecilia (2012): “Narrativas televisivas sobre conflictos sindicales". Ponencia presentada en las Terceras Jornadas Internacionales de Problemas latinoamericanos. Mendoza, Argentina, Universidad Nacional de Cuyo. Publicación completa en CD, ISBN: 978-987-9441-65-7.

Arias, Cora Cecilia; Haidar, Victoria (2008): "Resistir en nombre de la salud. Un análisis de la experiencia del Cuerpo de Delegados de los subterráneos de la Ciudad de Buenos Aires". Revista Trabajo y Sociedad. Santiago del Estero, Argentina, núm. 11.

Arias, Cora Cecilia et al. "La disputa estratégica. El caso Metrovías" en Colectivos resistentes. Procesos de politización de trabajadores en la Argentina reciente. Paula Abal Medina y Nicolás Diana Menéndez (comp,). Buenos Aires, Imago Mundi, p. 75-126.

Barthes, Roland (1980): Mitologías. México, Siglo XXI.

Borrat, Héctor (1989): El periódico, actor político. Barcelona, Gustavo Gili.

Farré, Marcela (2004): El noticiero como mundo posible. Estrategias ficcionales en la información televisiva. Buenos Aires, La Crujía.

Günther, Natalia (2007): “La representación de los trabajadores del subte y sus prácticas por Clarín. El discurso como arena de la 
lucha de clases". Ponencia presentada en las 4tas Jornadas de Jóvenes Investigadores. Buenos Aires, Instituto de Investigaciones Gino Germani.

Jost, François (2003): "La cotidianidad como modelo de la realidad televisual". Figuraciones. Buenos Aires, n 1-2: "Memoria del Arte/memoria de los medios", p. 107-119.

Martín Barbero, Jesús (1987): Procesos de comunicación y matrices de cultura. Itinerario para salir de la razón dualista. México, Gustavo Gilli. 